\title{
PEMIKIRAN SEJARAH DALAM MENGEMBANGKAN PEMBELAJARAN IPS
}

\author{
Muhammad Mukhlis \\ Email: 1810111310008@mhs.ulm.ac.id \\ Program Studi Pendidikan Sejarah Fakultas Keguruan dan Ilmu Pendidikan \\ Universitas Lambung Mangkurat \\ Banjarmasin
}

\begin{abstract}
Abstrak
Fungsi utama pendidikan adalah pengembangan kesadaran nasional sebagai sumber daya mental dalam proses pembangunan kepribadian nasional tersusun dari karakteristik perwatakan yang tumbuh serta melembaga dalam proses pengalaman sepanjang kehidupan bangsa, Dengan demikian kepribadian nasional serta identitas tertumpu pada pengalaman kolektif bangsa, yang bersifat historis (Sartono Kartodirdjo,1998:1). Sejarah merupakan disiplin ilmu yang menjadi bagian dari Mata Pelajaran IPS di Sekolah. Pembelajaran IPS lebih menekankan pada aspek pendidikan daripada transfer konsep karena dalam pembelajaran IPS peserta didik diharapkan memperoleh sikap, nilai, moral dan ketrampilannya berdasarkan konsep yang telah dimilikinya. Dengan demikian, pembelajaran IPS harus diformulasikan pada aspek kependidikannya.

Artikel ini diharapkan dapat memotivasi para tenaga pendidik untuk mengembangkan pemikiran sejarah kepada para siswa agar pembelajaran IPS menjadi menyenangkan dan dapat menarik minat para siswa dalam proses pembelajaran sejarah.
\end{abstract}

\section{PENDAHULUAN}

Banyak siswa melihat mata pelajaran IPS sebagai mata pelajaran yang mudah karena hanya membutuhkan hafalan dan menganggapnya sebagai mata pelajaran yang 
membosankan, sehingga pencapaian target pembelajaran sangat rendah. Untuk itu dibutuhkan alternatif pemikiran yang efektif dalam pembelajaran IPS agar dapat mengembangkan pencapaian target pembelajaran dan kompetensi berpikir, dan menciptakan pembelajaran IPS yang menyenangkan dan bermakna.

\section{PEMIKIRAN SEJARAH DALAM MENGEMBANGKAN PEMBELAJARAN IPS}

Di penghujung akhir abad 20, terutama pada dua dasawarsa terakhir, telah terjadi perubahan sosial yang sangat cepat di lingkungan masyarakat Indonesia. Perubahan sosial tersebut, sebagai akibat dari pelaksanaan pembangunan nasional dan proses modernisasi (Djoko Suryo, 1991: 5).

Beberapa faktor pokok yang menjadi penggerak perubahan sosial antara lain modernisasi teknologi, komersialisasi, industrialisasi, perkembangan demografis, revolusi komunikasi, transportasi dan birokrasi. Faktor pendidikan memiliki tempat yang penting dalam proses modernisasi. Pendidikan tidak hanya memperbatas kebodohan tetapi memberikan tenaga trampil dan terdidik yang dibutuhkan oleh proses pembangunan. Proses pembangunan yang menekankan pada pengenalan teknologi, industrialisasi, pengelolaan sumber daya, memerlukan dukungan pembinaan ketahanan dan kelestarian kesadaran berbangsa dan bermasyarakat.

Dalam kehidupan suatu bangsa, pendidikan mempunyai peranan yang sangat penting untuk menjamin perkembangan dan kelangsungan kehidupan bangsa yang bersangkutan. IPS mengkaji seperangkat peristiwa, fakta, konsep, dan generalisasi yang berkaitan dengan isu sosial. Melalui mata pelajaran IPS, peserta didik diarahkan untuk dapat menjadi warga negara Indonesia yang demokratis, dan bertanggungjawab, serta warga dunia yang cinta damai.

Sejarah merupakan disiplin ilmu yang menjadi bagian dari Mata Pelajaran IPS di Sekolah. Pembelajaran IPS lebih menekankan pada aspek pendidikan daripada transfer konsep karena dalam pembelajaran IPS peserta didik diharapkan memperoleh sikap, nilai, 
moral dan ketrampilannya berdasarkan konsep yang telah dimilikinya. Dengan demikian, pembelajaran IPS harus diformulasikan pada aspek kependidikannya.

Salah satu fungsi utama pendidikan adalah pengembangan kesadaran nasional sebagai sumber daya mental dalam proses pembangunan kepribadian nasional tersusun dari karakteristik perwatakan yang tumbuh serta melembaga dalam proses pengalaman sepanjang kehidupan bangsa, Dengan demikian kepribadian nasional serta identitas tertumpu pada pengalaman kolektif bangsa, yang bersifat historis (Sartono Kartodirdjo,1998:1). Pengajaran sejarah tidak boleh hanya menekankan aspek masa lampau saja. Untuk itu guru sejarah dituntut seperti guru mata pelajaran lainnya agar memiliki ketrampilan pengetahuan dan integritas yang tinggi dalam melaksanakan tugasnya.

Pengajaran sejarah harus mengembangkan aspek kualitas dan kuantitas bahan dan materinya. Penyajian materi secara mendalam, menggunakan metode internalisasi nilai yang terkandung dalam bahan tersebut. Pelajaran sejarah menjadi pelajaran yang berada di papan bawah, sehingga sering diremehkan, ditambah lagi guru sejarah kurang peka terhadap gejala-gejala sejarah, akibatnya metode yang dikembangkan, cenderung konvensional dan monoton yaitu metode DDCH (Dengar, Duduk, Cerita, Hambar) (Djoko Suryo, 1991: 5).

Tujuan pembelajaran dalam pendidikan IPS adalah untuk mengembangkan kompetensi berpikir siswa dalam untuk memecahkan masalah dan membangun kebiasaan ilmiah. Pembelajaran IPS mengacu pada holistik karakter siswa dalam melihat setiap peristiwa yang ada di sekitarnya dan bagaimana mereka menggunakan IPS dan pengetahuan pendidikan sebagai acuan dalam menganalisis masalah, khususnya masalah sosial.

Konsep sejarah menjadi salah satu landasan penting untuk melihat suatu peristiwa tertentu. Pada dasarnya, suatu peristiwa selalu berkaitan dengan waktu, kesinambungan dan perubahan (NCSS, 1994) dan juga berkaitan dengan peristiwa sebelumnya. Guru harus membekali siswa dengan seperangkat keterampilan, yaitu berpikir sejarah. Dengan begitu, 
setiap kali mereka menghadapi masalah, mereka akan selalu mengacu pada fakta, logika dan kronologi.

Menurut Nugroho Notosusanto (1979 : 3-5) setidak-tidaknya ada empat kegunaan dalam mempelajari sejarah, yaitu: (1) Kegunaan rekreatif; (2) Kegunaan inspiratif; (3) Fungsi instruktif, dan (4) Fungsi edukatif, yang masing-masing dapat dijelaskan sebagai berikut:

1) Kegunaan rekreatif

Dengan belajar sejarah akan dapat mengantarkan pada perlawatan untuk mengamati kehidupan masa lampau di berbagai pelosok negeri. Dengan demikian akan menghilangkan kejenuhan dalam kehidupan rutinitas dari kegiatan sehari-hari.

2) Kegunaan inspiratif

Fungsi ini terkait dengan suatu proses untuk memperkuat identitas dan mempertinggi dedikasi sebagai suatu bangsa. Dengan menghayati berbagai peristiwa dan kisah-kisah kepahlawanan, memperhatikan karya-karya besar dari para tokoh, akan memberikan kebanggaan dan makna yang begitu dalam bagi generasi muda. Karena itu, dengan mempelajari sejarah akan dapat mengembangkan inspirasi, imajinasi dan kreativitas generasi yang hidup sekarang dalam rangka hidup berbangsa dan bernegara. Fungsi inspirasi juga dapat dikaitkan dengan sejarah sebagai pendidikan moral. Sebab setelah belajar sejarah, seseorang dapat mengembangkan inspirasi dan berdasarkan keyakinannya dapat menerima atau menolak pelajaran yang terkandung dalam peristiwa sejarah yang dimaksud.

3) Fungsi instruktif

Yaitu sebagai alat bantu dalam proses pembelajaran. Dalam hal ini sejarah dapat berperan dalam upaya penyampaian pengetahuan dan keterampilan kepada subjek belajar.

4) Fungsi edukatif 
Maksudnya adalah bahwa sejarah dapat dijadikan pelajaran dalam kehidupan keseharian bagi setiap manusia. Sejarah juga mengajarkan tentang contoh yang sudah terjadi agar seseorang menjadi arif, sebagai petunjuk dalam berperilaku.

Melalui kegunaan dalam mempelajari sejarah tersebut diharapkan dapat mengembangkan pemikiran sejarah kepada para siswa dan menjadikannya sebagai alternatif dalam pembelajaran IPS.

\section{SIMPULAN}

Dalam kehidupan suatu bangsa, pendidikan mempunyai peranan yang sangat penting untuk menjamin perkembangan dan kelangsungan kehidupan bangsa yang bersangkutan. IPS mengkaji seperangkat peristiwa, fakta, konsep, dan generalisasi yang berkaitan dengan isu sosial. Melalui mata pelajaran IPS, peserta didik diarahkan untuk dapat menjadi warga negara Indonesia yang demokratis, dan bertanggungjawab, serta warga dunia yang cinta damai.

Sejarah merupakan disiplin ilmu yang menjadi bagian dari Mata Pelajaran IPS di Sekolah. Pembelajaran IPS lebih menekankan pada aspek pendidikan daripada transfer konsep karena dalam pembelajaran IPS peserta didik diharapkan memperoleh sikap, nilai, moral dan ketrampilannya berdasarkan konsep yang telah dimilikinya. Dengan demikian, pembelajaran IPS harus diformulasikan pada aspek kependidikannya.

\section{REFERENSI}

Hery Porda Nugroho Putro (2013). Historical Thinking In Learning Social Studies.

Sutiyono (2009). Materi Sejarah Dalam Pembelajaran IPS (Studi Kasus di SMK 3 Kudus) http://www.ssbelajar.net/2013/09/fungsi-sejarah-menurut-nugroho-notosusanto.html?m=1 